\title{
Inhibition of Indigoidine Synthesis as a High-Throughput Colourimetric Screen for Antibiotics Targeting the Essential Mycobacterium tuberculosis Phosphopantetheinyl Transferase PptT
}

\author{
Alistair S. Brown 1,2,3, Jeremy G. Owen ${ }^{1,2,3}$, James Jung ${ }^{3,4,+}$, Edward N. Baker ${ }^{3,4}$ and David F. Ackerley $1,2,3, *$ (D) \\ 1 School of Biological Sciences, Victoria University of Wellington, Wellington 6012, New Zealand; \\ alistair.brown@vuw.ac.nz (A.S.B.); jeremy.owen@vuw.ac.nz (J.G.O.) \\ 2 Centre for Biodiscovery, Victoria University of Wellington, Wellington 6012, New Zealand \\ 3 Maurice Wilkins Centre for Molecular Biodiscovery, Auckland 1142, New Zealand; \\ jjung@genzentrum.lmu.de (J.J.); en.baker@auckland.ac.nz (E.N.B.) \\ 4 School of Biological Sciences, University of Auckland, Auckland 1142, New Zealand \\ * Correspondence: david.ackerley@vuw.ac.nz; Tel.: +64-4-4635576 \\ † Current address: Gene Center and Department of Biochemistry, Ludwig-Maximilians-Universität München, \\ 81377 Munich, Germany.
}

Citation: Brown, A.S.; Owen, J.G.; Jung, J.; Baker, E.N.; Ackerley, D.F. Inhibition of Indigoidine Synthesis as a High-Throughput Colourimetric Screen for Antibiotics Targeting the Essential Mycobacterium tuberculosis Phosphopantetheinyl Transferase PptT. Pharmaceutics 2021, 13, 1066. https://doi.org/10.3390/ pharmaceutics 13071066

Academic Editors: Corneliu Tanase, Aura Rusu and Valentina Uivarosi

Received: 2 June 2021

Accepted: 9 July 2021

Published: 12 July 2021

Publisher's Note: MDPI stays neutral with regard to jurisdictional claims in published maps and institutional affiliations.

Copyright: (c) 2021 by the authors. Licensee MDPI, Basel, Switzerland. This article is an open access article distributed under the terms and conditions of the Creative Commons Attribution (CC BY) license (https:/ / creativecommons.org/licenses/by/ $4.0 /)$.

\begin{abstract}
A recently-validated and underexplored drug target in Mycobacterium tuberculosis is PptT, an essential phosphopantetheinyl transferase (PPTase) that plays a critical role in activating enzymes for both primary and secondary metabolism. PptT possesses a deep binding pocket that does not readily accept labelled coenzyme A analogues that have previously been used to screen for PPTase inhibitors. Here we report on the development of a high throughput, colourimetric screen that monitors the PptT-mediated activation of the non-ribosomal peptide synthetase BpsA to a blue pigment (indigoidine) synthesising form in vitro. This screen uses unadulterated coenzyme A, avoiding analogues that may interfere with inhibitor binding, and requires only a single-endpoint measurement. We benchmark the screen using the well-characterised Library of Pharmaceutically Active Compounds (LOPAC ${ }^{1280}$ ) collection and show that it is both sensitive and able to distinguish weak from strong inhibitors. We further show that the BpsA assay can be applied to quantify the level of inhibition and generate consistent $\mathrm{EC}_{50}$ data. We anticipate these tools will facilitate both the screening of established chemical collections to identify new anti-mycobacterial drug leads and to guide the exploration of structure-activity landscapes to improve existing PPTase inhibitors.
\end{abstract}

Keywords: PPTase; NRPS; indigoidine; PptT; antibiotic screening

\section{Introduction}

Despite diminishing rates of infection, the disease burden of Mycobacterium tuberculosis remains high, with 2019 seeing approximately 10 million people infected and 1.4 million deaths worldwide [1]. The emergence of drug-resistant strains of $M$. tuberculosis coupled with long treatment times has resulted in a pressing need for new therapeutics [2]. M. tuberculosis is difficult to treat effectively, in part due to its lipid-rich cell wall and envelope, which contain a diversity of unusual lipids that help it to survive and evade the host immune system [3-5]. Mega-synthetases, including the fatty acid synthetase (FAS) I and II systems and polyketide synthetases (PKSs), play crucial roles in the biosynthesis of these lipids [6]. A further megasynthetase family, the non-ribosomal peptide synthetases (NRPSs), is required to produce the important virulence factor mycobactin [7]. Each of these mega-synthetases requires the attachment of a phosphopantetheinyl (Ppant) arm to one or more carrier protein (CP) domain(s) to convert them from an inactive apo to an active holo form, a post-translational modification that is essential for functionality [8].

The attachment of the Ppant arm is catalysed by an enzyme superfamily called the $4^{\prime}$-phosphopantetheinyl transferases (PPTases), which in prokaryotes fall into two broad 
classes that differ in their structure and substrate specificity [8]. Type I (or AcpS type) PPTases are homotrimers that have a narrow substrate specificity and typically recognise acyl carrier protein (ACP) domains present in the FAS-I and FAS-II systems. Type II (or Sfp type) PPTases tend to be pseudodimers, have a much broader substrate specificity and typically activate ACP, peptidyl carrier protein (PCP) and aryl carrier protein (ArCP) domains present in PKSs and NRPSs [8]. Due to their lynchpin roles in both primary and secondary metabolism, many PPTases are essential [8] and have been identified as promising drug targets [9].

M. tuberculosis possesses both a Type I PPTase (AcpS) and a Type II PPTase (PptT) [10]. Although it activates the FAS-1 system [11], the essential nature of AcpS has not been confirmed in M. tuberculosis [10,12]. Conversely, PptT, which governs the activation of at least 18 PKSs [13], three NRPSs involved in the biosynthesis of the siderophore mycobactin [14] and AcpM (the standalone CP in the FAS-II system [11]), has been confirmed as essential for M. tuberculosis growth in vitro [12,13] and in murine models [13]. Importantly for drug targeting, even partial inhibition of PptT can be enough to kill M. tuberculosis [13]. This is likely because a Ppant hydrolase (PptH) that removes the Ppant from carrier proteins is expressed in the same operon as PptT, thereby restricting the ability of M. tuberculosis to upregulate PptT without also increasing PptH to detrimental levels [15]. PptT is a pseudodimer and has a broadly similar $\alpha / \beta$ fold to other crystallised Type-II PPTases with some minor variations, one of the most significant being that the Ppant arm extends into a deep hydrophobic pocket in the binding pocket [16,17]. By way of contrast, in the crystal structure of the well-characterised Type II PPTase, Sfp from Bacillus subtilis, the Ppant arm directs into the solvent [18] (Figure 1A).

Several high throughput screens to identify bacterial PPTase inhibitors have been developed that monitor the binding of fluorescently labelled coenzyme A (CoA) to a carrier protein or peptide, using either fluorescent polarisation or FRET-based detection [9,19-21]. However, rather than directly targeting the PPTase of a pathogenic species, these screens have all employed the canonical PPTase Sfp from B. subtilis as a surrogate. This is problematic for discovering inhibitors of $M$. tuberculosis PptT, as it does not accept fluorescent CoA analogues as readily as Sfp [13], due to its deeper binding pocket (Figure 1A) [16,17]. It is also noteworthy that 8918 , a promising PptT inhibitor that was recently identified in a whole-organism screen against $M$. tuberculosis, binds to the PptT active site, close to the Ppant arm [15]. Fluorescent analogues of $\mathrm{CoA}$, which are substantially bulkier than native CoA, may therefore exclude otherwise promising inhibitors from the active site. With this in mind, we considered it important to develop a cost-effective direct screen against PptT that uses unadulterated CoA as a substrate.

We have previously shown that the NRPS BpsA (blue pigment synthetase A) could be used to assess the relative levels of inhibition of Sfp and two Pseudomonas Type II bacterial PPTases by the generic inhibitor 6-nitroso-1,2-benzopyrone [22]. BpsA is a singlemodule NRPS that in vitro can convert two molecules of L-glutamine into the blue pigment indigoidine, provided it can been activated to the holo form by a co-incubated PPTase (Figure 1B) [23]. Here we demonstrate that recombinant BpsA purified in the apo form can be used to provide a robust and high-throughput screen for compounds that inhibit PptT from activating BpsA. 
A

Sfp

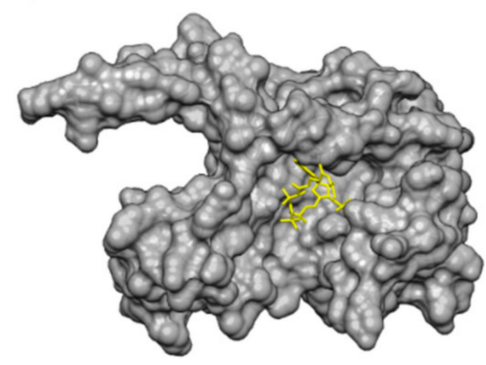

B<smiles>NC(=O)CCC(N)C(=O)O</smiles>

L-GIn

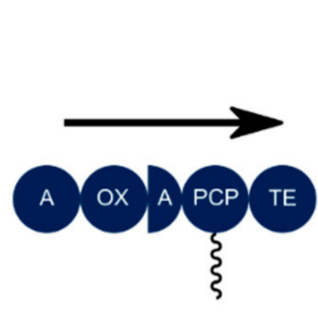

2x ATP Holo-BpsA<smiles>NC1=CC(=C2C=C(N)C(=O)NC2=O)C(=O)NC1=O</smiles>

Indigoidine
PptT

C

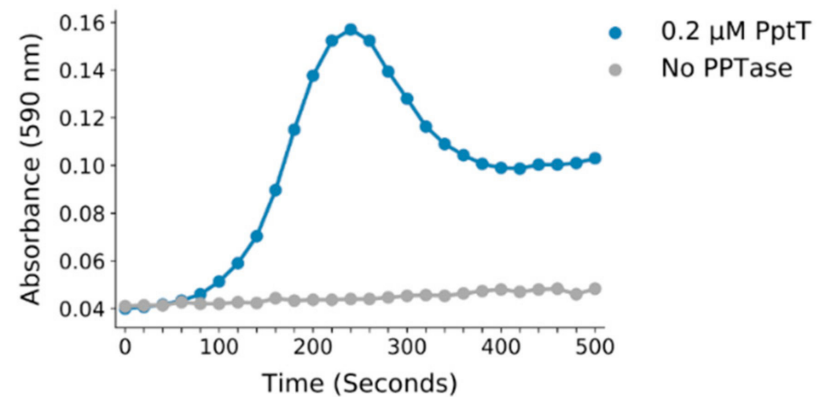

Figure 1. (A) Crystal structures of Sfp and PptT, highlighting the orientation of CoA: CoA (yellow) is orientated towards the solvent in the crystal structure of Sfp (PDB: 1QR0), while in our structure of PptT (PDB:4QVH), it is encapsulated by the binding pocket. Visualisation was performed using Chimera [24]. (B) Schematic showing biosynthesis of indigoidine by holo-BpsA: Holo-BpsA synthesises indigoidine from two molecules of L-glutamine in an ATP powered reaction. When indigoidine is solubilised in DMSO, it has a characteristic deep blue colouring that can readily be detected by monitoring absorbance at $590 \mathrm{~nm}$. (C) Characteristic curve of indigoidine biosynthesis during the activation of apo-BpsA by PptT: Indigoidine production in an aqueous solution yields a sigmoidal curve of absorbance at $590 \mathrm{~nm}$ until it reaches saturation and precipitates, after which the $\mathrm{A}_{590}$ drops.

\section{Materials and Methods}

\subsection{Materials and Reagents}

Unless otherwise stated, chemicals, media and reagents used in this study were supplied by Sigma-Aldrich (St Louis, MO, USA), Thermo Fisher Scientific (Waltham, MA, USA), Duchefa Biochemie (BH Haarlem, Netherlands) or New England Biolabs (Ipswich, MA, USA). Sanguinarine chloride for kinetic screening was supplied by Sapphire Biosciences (Redfern, NSW, Australia).

\subsection{Plasmid Construction}

Construction of the BpsA expression plasmid pCDFDUET1::bpsA was described previously [22]. Construction of NOHISPET::pcpS, which expresses an untagged version of the broad-spectrum PPTase PcpS to covert apo-BpsA to holo-BpsA and not co-purify during Ni-NTA chromatography, was as previously described [25]. pET28a(+)::pptT was constructed by amplifying pptT from $M$. tuberculosis H37Ra genomic DNA using the primers CCCCCATATGGACGGTAGGCACGCTG and CCCCCTCGAGTCATAGCACGATCGCGGT (restriction sites underlined). The amplified gene was ligated into pET28a $(+)$ between the NdeI and XhoI restriction sites.

\subsection{Protein Expression}

All protein expression used E. coli BL21(DE3) $\Delta e n t D$ [26] as an expression strain. Cultures were grown in lysogeny broth (LB) with plasmid appropriate antibiotics (spectinomycin $100 \mu \mathrm{g} / \mathrm{mL}$, kanamycin $50 \mu \mathrm{g} / \mathrm{mL}$ ). Fresh $400 \mathrm{~mL}$ expression cultures were 
inoculated to an $\mathrm{A}_{600}$ of 0.1 overnight and incubated at $37^{\circ} \mathrm{C}, 200 \mathrm{rpm}$ until an $\mathrm{A}_{600}$ of between 0.6 and 0.8 was obtained. The cultures were then chilled on ice for approximately $30 \mathrm{~min}$. Protein expression was induced with the addition of IPTG to a final concentration of $0.5 \mathrm{mM}$. The cultures were then incubated for $24 \mathrm{~h}$ at $18^{\circ} \mathrm{C}, 200 \mathrm{rpm}$ before harvesting by centrifugation $\left(2700 \times g, 20 \mathrm{~min}, 4{ }^{\circ} \mathrm{C}\right)$. The cell pellets were then stored at $-80^{\circ} \mathrm{C}$ until needed.

\subsection{Protein Purification}

PPTases were purified using standard Tris-Cl Ni-NTA chromatography buffers with the following modification: the bind, wash and elute buffers were supplemented with $25 \% v / v$ glycerol to enhance protein stability. The eluted PPTases were then desalted using a HiTrap desalting column (Cytiva, Marlborough, MA, USA) with a desalting buffer of $50 \mathrm{mM}$ Tris- $\mathrm{Cl}(\mathrm{pH} 7.8)$ and $12.5 \%$ glycerol $(v / v)$. The buffer composition was then adjusted to a final concentration of $40 \%(\mathrm{v} / \mathrm{v})$ glycerol, and aliquots were stored at $-80{ }^{\circ} \mathrm{C}$ until needed. Apo and holo-BpsA were purified as previously described [25].

\subsection{Optimisation of Enzyme Concentrations}

To determine the optimal concentration of BpsA for the detection of PptT inhibition, $30 \mu \mathrm{L}$ of reaction mix comprising $50 \mathrm{mM}$ Tris- $\mathrm{Cl}(\mathrm{pH} 8.0), 10 \mathrm{mM} \mathrm{MgCl} 2$ and $5 \mathrm{mM}$ ATP was added to individual wells of a standard 96 well plate. Next, $10 \mu \mathrm{L}$ holo-BpsA (purified and activated as previously described [25]) was added to each well to give a range of final concentrations $(0-1 \mu \mathrm{M})$. To initiate indigoidine synthesis, $10 \mu \mathrm{L}$ of $5 \mathrm{mM}$ L-glutamine was added to each well. The plate was then shaken at $1000 \mathrm{rpm}$ for $10 \mathrm{~s}$ and incubated at room temperature for $1 \mathrm{~h}$. The indigoidine was then resolubilised by the addition of $200 \mu \mathrm{L}$ DMSO and then incubated at $37^{\circ} \mathrm{C}$ with shaking at $200 \mathrm{rpm}$ for $0.5 \mathrm{~h}$. A Perkin Elmer Enspire Plate reader was then used to record the absorbance readings at $590 \mathrm{~nm}$.

To determine the optimal concentration of PptT for the detection of inhibitors, $10 \mu \mathrm{L}$ of PPTase mix comprising $50 \mathrm{mM}$ Tris- $\mathrm{Cl}(\mathrm{pH}$ 8.0) and PptT at a range of concentrations $(0-0.5 \mu \mathrm{M})$ was added to individual wells of a standard 96 well plate. To initiate indigoidine synthesis, $40 \mu \mathrm{L}$ of a reaction mix comprising $50 \mathrm{mM}$ Tris- $\mathrm{Cl}$ ( $\mathrm{pH} 8.0), 10 \mathrm{mM} \mathrm{MgCl}_{2}, 5 \mathrm{mM}$ ATP, $5 \mathrm{mM}$ L-glutamine, $10 \mu \mathrm{M}$ CoA and $0.6 \mu \mathrm{M}$ apo-BpsA was added to each well. The plate was then shaken at $1000 \mathrm{rpm}$ for $10 \mathrm{~s}$ and incubated at room temperature for $1 \mathrm{~h}$. The indigoidine was then resolubilised by the addition of $200 \mu \mathrm{L}$ DMSO and incubated at $37^{\circ} \mathrm{C}$ with shaking at $200 \mathrm{rpm}$ for $0.5 \mathrm{~h}$. A Perkin Elmer Enspire plate reader was then used to record the absorbance of each well at $590 \mathrm{~nm}$.

\subsection{Z-Factor Calculation}

To determine the Z-factor of the screen, 80 reactions were established in columns 2-11 of a standard 96 well-plate. Each was prepared from $30 \mu \mathrm{L}$ of reaction mix comprising $50 \mathrm{mM}$ Tris- $\mathrm{Cl}(\mathrm{pH} 8.0), 0.01 \%(v / v)$ Triton- $\mathrm{X}, 10 \mathrm{mM} \mathrm{MgCl} 2,5 \mathrm{mM}$ ATP, $5 \mathrm{mM}$ L-glutamine and $10 \mu \mathrm{M}$ CoA. Next, $10 \mu \mathrm{L}$ PPTase mix containing either $0.4 \mu \mathrm{M}$ PptT and $50 \mathrm{mM}$ Tris-Cl ( $\mathrm{pH}$ 8.0) (or else unadulterated $50 \mathrm{mM}$ Tris- $\mathrm{Cl}(\mathrm{pH}$ 8.0) as a negative control) was added to each well. To initiate indigoidine synthesis, $10 \mu \mathrm{L}$ of $0.6 \mu \mathrm{M}$ apo-BpsA in $50 \mathrm{mM}$ Tris-Cl ( $\mathrm{pH}$ 8.0) was added to each well. The plate was then shaken at $1000 \mathrm{rpm}$ for $10 \mathrm{~s}$ and incubated at room temperature for $1 \mathrm{~h}$. The indigoidine was then resolubilised by the addition of $200 \mu \mathrm{L}$ DMSO and incubated at $37^{\circ} \mathrm{C}$ with shaking at $200 \mathrm{rpm}$ for $0.5 \mathrm{~h}$. A Perkin Elmer Enspire plate reader was then used to record the absorbance readings at $590 \mathrm{~nm}$. To calculate the Z-factor, the following equation was used (derived from the method of Zhang et al. [27]), with $\sigma$ representing the standard deviation, $\mu$ representing the means and $\rho$ representing the positive and $\mathrm{n}$ the negative control.

$$
Z \text { factor }=1-\frac{3\left(\sigma_{\rho}+\sigma_{n}\right)}{\left|\mu_{\rho}-\mu_{n}\right|}
$$




\subsection{Screening of the LOPAC ${ }^{1280}$ Collection and $E C_{50}$ Calculations}

The Sigma-Aldrich LOPAC ${ }^{1280}$ collection was first diluted to a working stock of $500 \mathrm{mM}$ per compound. To screen the collection, 88 reactions at a time were established in columns 1-11 of a standard 96 well-plate. Each was prepared from $30 \mu \mathrm{L}$ of reaction mix comprising $50 \mathrm{mM}$ Tris- $\mathrm{Cl}(\mathrm{pH} 8.0), 0.01 \%(v / v)$ Triton- $\mathrm{X}, 10 \mathrm{mM} \mathrm{MgCl} 2,5 \mathrm{mM}$ ATP, $5 \mathrm{mM}$ L-glutamine and $10 \mu \mathrm{M}$ CoA. Next, a CyBio liquid handler was used to pin $2 \mu \mathrm{L}$ of compound into columns $2-11$ and $2 \mu \mathrm{L}$ of DMSO into column 1. To screen for PptT inhibitors, $10 \mu \mathrm{L}$ of PPTase mix comprising a freshly-prepared stock of $0.4 \mu \mathrm{M}$ PptT and $50 \mathrm{mM}$ Tris- $\mathrm{Cl}$ ( $\mathrm{pH}$ 8.0) was added to wells A1-C1 and columns 2-11 (see Supplementary Figure S1). To initiate indigoidine synthesis, $10 \mu \mathrm{L}$ of $0.6 \mu \mathrm{M}$ apo-BpsA in $50 \mathrm{mM}$ Tris-Cl ( $\mathrm{pH}$ 8.0) was added to each well. To screen for holo-BpsA inhibitors, an equivalent screening format was established only using $0.6 \mu \mathrm{M}$ holo-BpsA and with no PPTase mix added. Each plate was then shaken at $1000 \mathrm{rpm}$ for $10 \mathrm{~s}$ and incubated at room temperature for $1 \mathrm{~h}$. Indigoidine was then resolubilised by the addition of $200 \mu \mathrm{L}$ DMSO and incubation at $37^{\circ} \mathrm{C}$ with shaking at $200 \mathrm{rpm}$ for $0.5 \mathrm{~h}$. A Perkin Elmer Enspire plate reader was then used to record the absorbance readings at $590 \mathrm{~nm}$. The Python package Pandas [28] was used to process the data, which was then visualised using the Python package Seaborn [29].

To calculate the $\mathrm{EC}_{50}$ values of inhibitors, a two-fold serial dilution between $40 \mu \mathrm{M}$ and $0.625 \mu \mathrm{M}$ of each compound was established in $30 \mu \mathrm{L}$ reaction mixes comprising $50 \mathrm{mM}$ Tris- $\mathrm{Cl}(\mathrm{pH} 8.0)$, triton- $\mathrm{X} 0.01 \%(v / v), 10 \mathrm{mM} \mathrm{MgCl} 2,5 \mathrm{mM}$ ATP, $5 \mathrm{mM}$ L-glutamine and $10 \mu \mathrm{M} \mathrm{CoA}$ in replicate rows of a 96 well plate. To screen for PptT inhibitors, $10 \mu \mathrm{L}$ of PPTase mix comprising a freshly-thawed stock of $0.4 \mu \mathrm{M} \mathrm{PptT} \mathrm{in} 50 \mathrm{mM}$ Tris- $\mathrm{Cl}(\mathrm{pH}$ 8.0) was added. To initiate indigoidine synthesis, $10 \mu \mathrm{L}$ of $0.6 \mu \mathrm{M}$ apo-BpsA in $50 \mathrm{mM}$ Tris-Cl ( $\mathrm{pH}$ 8.0) was added to each well. The plate was then shaken at $1000 \mathrm{rpm}$ for $10 \mathrm{~s}$ and incubated at room temperature for $1 \mathrm{~h}$. Indigoidine was resolubilised by the addition of $200 \mu \mathrm{L}$ DMSO and incubation at $37^{\circ} \mathrm{C}$ with shaking at $200 \mathrm{rpm}$ for $0.5 \mathrm{~h}$. A Perkin Elmer Enspire plate reader was then used to record the absorbance readings at $590 \mathrm{~nm}$. The percentage inhibition at each compound concentration was then compared to a DMSO only control, and GraphPad Prism 9.0 was used to fit a four parameter dose-response curve.

\subsection{Kinetic Analysis of PptT Inhibition}

To calculate the inhibition of PptT by 6-nitroso-1,2-benzopyrone and sanguinarine chloride, a serial dilution between $200 \mu \mathrm{M}$ and $0.2 \mu \mathrm{M}$ was established for each compound in $30 \mu \mathrm{L} 50 \mathrm{mM}$ Tris- $\mathrm{Cl}(\mathrm{pH} 8.0)$ and Triton- $\mathrm{X} 0.01 \%(v / v)$ across individual rows of a standard 96 well plate. Next, $35 \mu \mathrm{L}$ of a PPTase mix comprising a freshly-thawed stock of $0.4 \mu \mathrm{M}$ PptT, $50 \mathrm{mM}$ Tris- $\mathrm{Cl}(\mathrm{pH} 8.0)$ and Triton-X $0.01 \%(v / v)$ was added to each well. To initiate indigoidine synthesis, a $35 \mu \mathrm{L}$ reaction mix comprising $0.01 \%(v / v)$ Triton- $X$, $50 \mathrm{mM}$ Tris- $\mathrm{Cl}$ (pH 8.0), $10 \mathrm{mM} \mathrm{MgCl} 2,5 \mathrm{mM}$ ATP, $5 \mathrm{mM}$ L-glutamine, $10 \mu \mathrm{M} \mathrm{CoA}$ and $0.6 \mu \mathrm{M}$ apo-BpsA was added to each well. The plate was then shaken at $1000 \mathrm{rpm}$ for $10 \mathrm{~s}$, and absorbance readings at $590 \mathrm{~nm}$ were read every $20 \mathrm{~s}$. To determine the $\mathrm{EC}_{50}$ values, the maximum indigoidine synthesis velocities were determined as described previously [22], and four-parameter dose-response curves were fitted using GraphPad Prism version 9.0.

\section{Results}

To determine whether BpsA could be used to screen for inhibitors of PptT, it was first necessary to show that PptT is capable of activating BpsA from the inactive apo to active holo form. BpsA was purified in the apo form from the Type II PPTase null E. coli strain BL21 $\Delta e n t D[26]$ and co-incubated with purified PptT. We and others $[16,17,30]$ have found PptT to be quite unstable in aqueous solutions, with it rapidly aggregating and losing activity. This necessitated freshly thawed PptT (purified and stored on glycerol at $-80^{\circ} \mathrm{C}$ ) to be used for each assay. Nonetheless, PptT was capable of rapidly activating apo-BpsA in vitro, yielding a typical indigoidine synthesis curve that reflects an initial burst of indigoidine synthesis followed by subsequent indigoidine precipitation [22] (Figure 1C). 
In our previous demonstration that BpsA could be used to quantify the strength of PPTase inhibition by the broad-specificity PPTase inhibitor 6-nitroso-1,2-benzopyrone, we monitored the change in velocity of indigoidine synthesis via continuous kinetic measurements [22]. We have since developed BpsA as a biosensor to measure glutamine [25] and ATP [31] and in so doing observed that end-point measurements post-solubilisation of the total indigoidine in $80 \%$ DMSO yielded more consistent data. To implement a similar approach here to quantify inhibition of PptT, we first assayed pre-activated holo-BpsA at a concentration range from 0 to $1 \mu \mathrm{M}$ in $50 \mu \mathrm{L}$ reactions. This enabled us to identify $0.6 \mu \mathrm{M}$ BpsA as an enzyme concentration that could provide a robust signal within the linear range of the assay, in a volume that could accommodate the addition of DMSO to $80 \%$ $(v / v)$ without exceeding the well capacity of a standard 96-well plate (Figure 2A). We then identified $0.4 \mu \mathrm{M} \mathrm{PptT}$ as a suitable concentration of target PPTase that, in the absence of inhibitor, induced a strong indigoidine synthesis signal when co-incubated with $0.6 \mu \mathrm{M}$ apo-BpsA (Figure 2B).

A

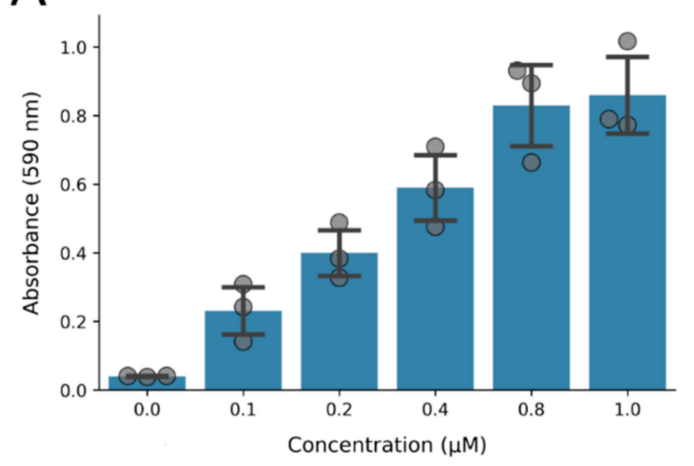

C

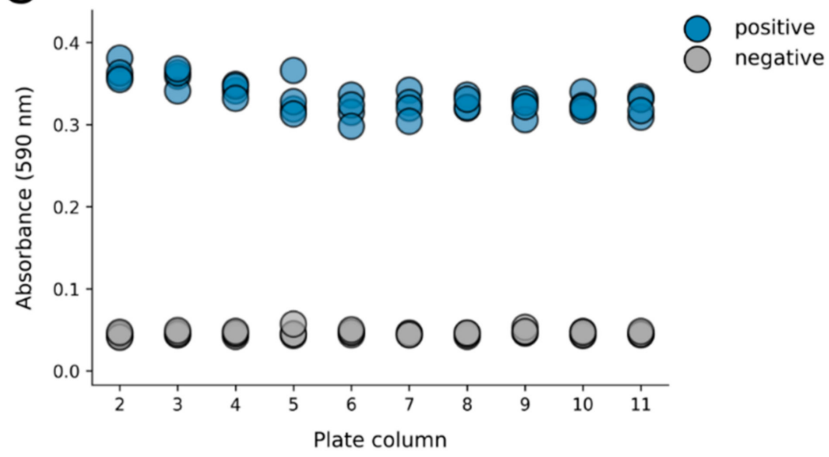

B

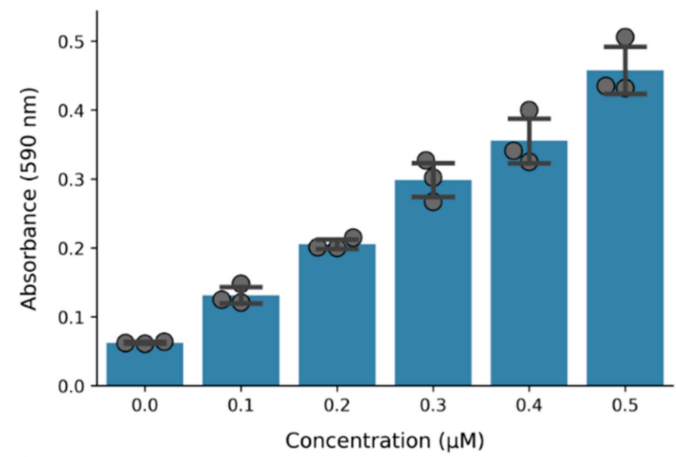

$\begin{array}{lllllllllll}2 & 3 & 4 & 5 & 6 & 7 & 8 & 9 & 10 & 11 & \text { Column }\end{array}$

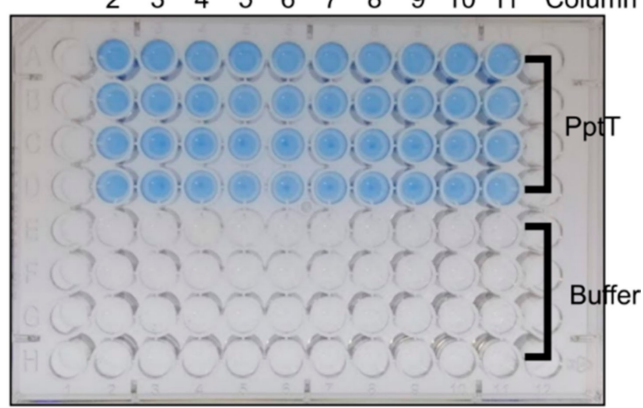

Figure 2. Optimisation of assay parameters: (A) increasing concentrations of holo-BpsA were added to a reaction mix containing $10 \mathrm{mM} \mathrm{MgCl}_{2}, 5 \mathrm{mM}$ ATP and $50 \mathrm{mM}$ Tris- $\mathrm{Cl}$ ( $\mathrm{pH}$ 8.0). The reaction was then initiated by addition of $5 \mathrm{mM}$ L-glutamine and incubated for $1 \mathrm{~h}$. The indigoidine was then resolubilised by the addition of DMSO, which gave a linear increase in absorbance until the assay began to saturate at an $\mathrm{A}_{590}$ of approximately 1.0. Data are the averages of three independent replicates and error bars represent one standard deviation. (B) Increasing concentrations of PptT were added to a reaction mix containing $10 \mathrm{mM} \mathrm{MgCl}_{2}, 5 \mathrm{mM}$ ATP, $5 \mathrm{mM}$ L-glutamine, $0.6 \mu \mathrm{M}$ apo-BpsA and $10 \mu \mathrm{M}$ CoA. The reaction was incubated for $1 \mathrm{~h}$ and then resolubilised by the addition of DMSO, and $\mathrm{A}_{590}$ values were recorded. A higher concentration of PptT resulted in an increased absorbance reading, indicating that a single endpoint assay can be used to detect inhibition. Data are the averages of three independent replicates, and error bars represent one standard deviation. (C) To determine the $\mathrm{Z}^{\prime}$ factor of the screen, a reaction mix was established in columns 2-11 comprising $0.01 \%$ triton $\mathrm{X}, 50 \mathrm{mM} \mathrm{Tris-Cl}(\mathrm{pH} 8.0$ ), $10 \mathrm{mM} \mathrm{MgCl}_{2}, 5 \mathrm{mM}$ ATP, $5 \mathrm{mM}$ L-glutamine and $10 \mu \mathrm{M} \mathrm{CoA}$. Next, PptT (to a final concentration of $0.4 \mu \mathrm{M}$ ) and buffer were added to rows 1-4, while only buffer was added to rows 5-8. To initiate each reaction, $0.6 \mu \mathrm{M}$ apo-BpsA was added. The $\mathrm{A}_{590}$ values for rows containing PptT (blue, positive) and the buffer controls (grey, negative) were recorded following a $1 \mathrm{~h}$ incubation and subsequent solubilisation with DMSO. (D) A photo of the plate from the experiment described for panel $\mathrm{C}$ following solubilisation by DMSO. The plate was placed on a light box prior to taking the photo. 
To validate the performance of the assay under conditions similar to a high throughput screen, we compared 80 reactions in a 96 well plate. A screening master mix comprising buffer, all requisite substrates (CoA, ATP and L-glutamine) and $0.01 \%$ Triton X-100 (to minimise nonspecific inhibitory activity from compounds that induce protein aggregation [32]) was aliquoted into each well. Next, PptT was added to 40 of the wells (to a final concentration of $0.4 \mu \mathrm{M}$ ), while the other 40 wells received only buffer to simulate reactions in which PptT had been completely inhibited. Finally, apo-BpsA was added to each well (to a final concentration of $0.6 \mu \mathrm{M}$ ) to initiate indigoidine synthesis, where possible. Following incubation for $1 \mathrm{~h}$ at room temperature, each $50 \mu \mathrm{L}$ reaction was stopped by the addition of $200 \mu \mathrm{L}$ of DMSO to solubilise the indigoidine, after which the $\mathrm{A}_{590}$ was measured (Figure 2C). The calculated $Z^{\prime}$-factor for the assay was 0.77 . This is a key measure of quality for high-throughput screens that derives from the separation of positive and negative control data; a Z'-factor above 0.5 represents 12 standard deviations of separation between the controls and hence a highly robust screen [27].

Having established the assay parameters, we then screened 1280 drug-like compounds from the Sigma-Aldrich library of pharmacologically active compounds (LOPAC ${ }^{1280}$ ) to identify inhibitors of PptT (a schematic of the complete high-throughput screening procedure is presented in Figure S3A). The LOPAC ${ }^{1280}$ collection is widely used for screen validation studies and has previously been found to contain a diverse range of inhibitors of B. subtilis Sfp [19], giving us confidence that it was likely to contain a diversity of PptT inhibitors also. Each screening plate contained 80 compounds arrayed in columns $2-11$. Three no-inhibitor positive controls and three negative controls lacking PptT were arrayed in column 1 of the screening plate, while column 12 was left empty (Supplementary Figure S1). The percentage activity for each well was then calculated relative to the average of the three positive controls located on each plate, revealing that 21 compounds caused $\geq 50 \%$ reduction in indigoidine levels (Figure 3B). Position effects were evident, owing to the instability of PptT upon addition to the aqueous reaction mix (in a row-by-row fashion using a multi-well pipette), which yielded a wave-like pattern of $A_{590}$ readings from row to row (Supplementary Figure S2A). This phenomenon was not observed in a counter-screen that was conducted using pre-activated holo-BpsA, to eliminate any compounds that were inhibiting BpsA rather than PptT (Supplementary Figure S2B). While it is possible that variation in the levels of soluble PptT may have confounded identification of some weak PptT inhibitors, most of the 21 "hits" yielded data that were clearly separated from the baseline (Figure 3B, dashed line).

In counter-screening the LOPAC ${ }^{1280}$ collection against pre-activated holo-BpsA (Supplementary Figure S3B), four compounds were identified as inhibiting indigoidine synthesis rather than being PptT-specific: ebselen, suramin hexasodium, chlorprothixene hydrochloride and 4-chloromercuribenzoic acid. Chlorprothixene hydrochloride did not register as an inhibitor of PptT and may have been a false positive in this counterscreen, while the other three were discarded from further consideration as likely pan assay interference compounds (PAINS) [33].

We next quantified the inhibition conferred by each of the 18 remaining compounds, using two-fold serial dilutions $(40 \mu \mathrm{M}$ to $0.3 \mu \mathrm{M})$ of each compound added to a PptT/apoBpsA reaction mix to generate $\mathrm{EC}_{50}$ values (Supplementary Figure S3). In one case (8-hydroxy-DPAT hydrobromide), no inhibitory activity was observed, indicating this was likely a false positive from our initial screen, while for nine of the remaining cases, the level of inhibition was insufficient to calculate meaningful $\mathrm{EC}_{50}$ values. Ultimately, we were able to confirm and quantify eight effective inhibitors of PptT (Table 1). Other than tyrphostin AG 537 and tyrphostin AG 538, all of these compounds had previously been reported as inhibitors of the canonical PPTase Sfp from B. subtilis [32]. 

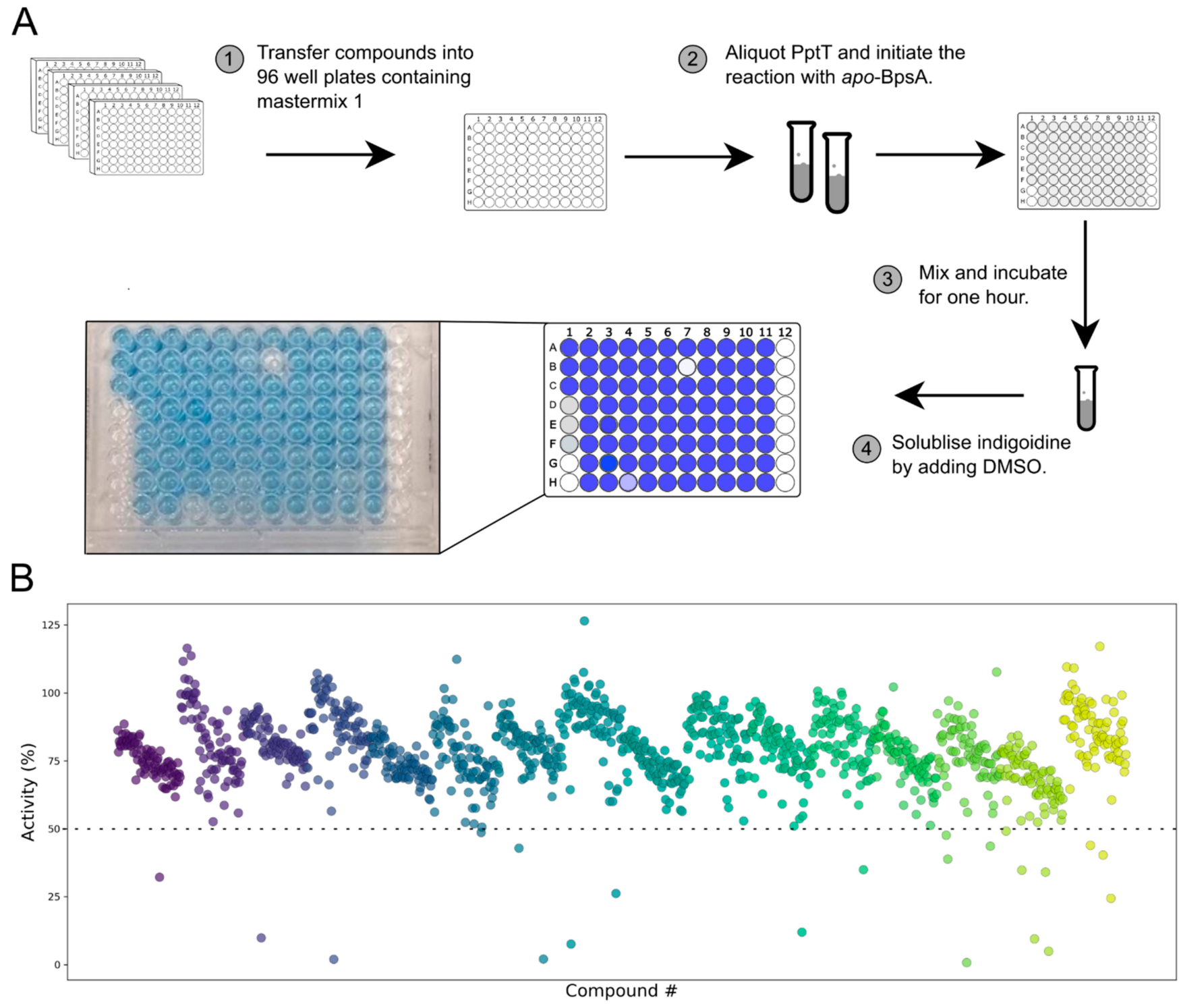

Figure 3. High-throughput screening of the LOPAC ${ }^{1280}$ library: (A) schematic diagram illustrating the screening process; (B) percentage activity of each compound in the library, with data derived from distinct 96 well plates presented in different colours. 
Table 1. PptT inhibitors recovered from BpsA screen. Names and descriptions were derived from the LOPAC ${ }^{1280}$ manifest. $\mathrm{EC}_{50}$ averages were calculated from three independent replicates \pm standard error.

\begin{tabular}{|c|c|c|c|}
\hline Name & Known Drug Activities & $\%$ Activity in PptT Screen & $\mathrm{EC}_{50}(\mu \mathrm{M})$ \\
\hline Aurintricarboxylic acid & DNA topoisomerase II inhibitor & 32 & $4.8 \pm 0.9$ \\
\hline SCH-202676 hydrobromide & Allosteric agonist and antagonist of GPCRs & 0.7 & $5.9 \pm 0.1$ \\
\hline Tyrphostin AG 537 & EGFR protein tyrosine kinase inhibitor & 35 & $5.9 \pm 0.5$ \\
\hline Disulfiram & Alcohol dehydrogenase inhibitor & 9 & $6.0 \pm 1.5$ \\
\hline Tyrphostin AG 538 & (IGF-1) receptor protein tyrosine kinase inhibitor & 24 & $6.4 \pm 0.7$ \\
\hline Bay 11-7085 & Inhibitor of NFKB & 10 & $7.4 \pm 0.4$ \\
\hline U-73122 & Phospholipase $\mathrm{C}$ and $\mathrm{A} 2$ inhibitor & 44 & $8.1 \pm 0.5$ \\
\hline 6-Nitroso-1,2-benzopyrone & Poly(ADP-ribose) ligand & 12 & $8.3 \pm 1.7$ \\
\hline 6-Hydroxy-DL-DOPA & Precursor of the catecholaminergic neurotoxin & 26 & N.D. ${ }^{1}$ \\
\hline Tyrphostin AG 808 & Protein tyrosine kinase inhibitor & 34 & N.D. ${ }^{1}$ \\
\hline I-OMe-Tyrphostin AG 538 & (IGF-1) receptor protein tyrosine kinase inhibitor & 40 & N.D. ${ }^{1}$ \\
\hline Reactive Blue 2 & P2Y receptor antagonist & 38 & N.D. ${ }^{1}$ \\
\hline GW5074 & cRaf1 kinase inhibitor & 43 & N.D. ${ }^{1}$ \\
\hline PD 404, 182 & KDO-8-P synthase inhibitor & 35 & N.D. ${ }^{1}$ \\
\hline Sanguinarine chloride & Inhibitor of ATPase & 44 & N.D. ${ }^{1}$ \\
\hline 7,7-Dimethyl-(5z,8z)-eicosadienoic acid & Phospholipase A2 and lipoxygenase inhibitor & 49 & N.D. ${ }^{1}$ \\
\hline Rottlerin & PKC and CaM kinase III inhibitor & 48 & N.D. ${ }^{1}$ \\
\hline
\end{tabular}

${ }^{1}$ N.D. = not determined, i.e., binding was insufficiently strong to permit a robust curve to be fitted to determine an EC 50 value.

In other work, we recently screened the LOPAC ${ }^{1280}$ collection against the SARS-CoV-2 protease using a FRET-based reporter and noticed that 8 of our 17 candidate PptT inhibitors (PD 404, 182, Disulfiram, U-73122, 6-nitroso-1,2-benzopyrone, aurintricarboxylic acid, sanguinarine chloride, Bay 11-7085 and 6-hydroxyl-DL-DOPA) also gave hits as strong protease inhibitors [34]. This suggested to us that many of these compounds may be generic enzyme inhibitors rather than specific for PptT. To further probe the specificity of hit compounds for PptT, we re-screened each for inhibition of holo-BpsA at a higher concentration of $40 \mu \mathrm{M}$ (Supplementary Figure S4). In this higher-concentration counterscreen, SCH 202626, previously identified as a broad-spectrum PPTase inhibitor [19], became noticeably inhibitory of holo-BpsA. Only five compounds exhibited less than $15 \%$ inhibition of holo-BpsA: 6-nitroso-1,2-benzopyrone, 6-hydroxy-DL-DOPA, 7,7-dimethyl(5Z,8Z)-eicosadienoic acid, disulfiram and sanguinarine chloride.

We next sought to benchmark our DMSO-resolubilisation end-point assay against the kinetic assay we had previously described [22]. For this, we selected two compounds with different inhibition profiles, namely 6-nitroso-1,2-benzopyrone, which has been shown to have activity in vitro against numerous PPTases $[19,22,35]$ and in vivo against the fungus Aspergillus fumigatus in a PPTase dependant manner [36], and the weaker inhibitor sanguinarine chloride, which has been previously reported as an inhibitor of both Sfp from $B$. subtilis [21] and M. tuberculosis PptT [16]. We used identical enzymatic concentrations across both assays to permit a direct comparison. In the kinetic assay, we derived an $\mathrm{EC}_{50}$ value of $4.4 \pm 1.2 \mu \mathrm{M}$ for 6-nitroso-1,2-benzopyrone (Supplementary Figure S5A), which is similar to the $\mathrm{EC}_{50}$ value of $8.3 \mu \mathrm{M}$ we calculated from our endpoint assay. However, the kinetic assay data for sanguinarine chloride was more variable (Supplementary Figure S5B), and GraphPad Prism 9.0 was unable to fit a robust curve. Based on this, we conclude that the endpoint assay is more sensitive and reproducible than the kinetic assay, at least at the tested enzyme concentrations.

\section{Discussion}

Here, we report on the development, optimisation and validation of a simple highthroughput assay to rapidly identify inhibitors of the promising antibiotic target PptT from M. tuberculosis. We validated the assay by screening the LOPAC ${ }^{1280}$ collection from Sigma-Aldrich. To the best of our knowledge, this is the first reported direct chemical library screen for inhibitors of PptT. From this screen we identified 18 inhibitors, but further investigation indicated that ten of these were non-specific compounds that also inhibited holo-BpsA when added at higher concentrations. Of the remaining eight, two were novel 
PPTase inhibitors that may be specific for PptT, while six had previously been identified as inhibitors of the B. subtilis canonical Type II PPTase Sfp, providing evidence by association for the efficacy of our screen. Finally, we compared our optimised end-point assay against a kinetic BpsA assay we had employed earlier [22] and concluded that the optimised assay is more amenable to high-throughput screening.

Two other assays have been developed to evaluate possible inhibitors of PptT. The first uses a scintillation proximity assay that is substantially more complex than our simple colourimetric BpsA assay, requiring radiolabelled $\mathrm{CoA}$ and a scintillation counting machine, and validation against PPTase inhibitors has not yet been reported [13]. The second assay uses rhodamine-labelled CoA to provide a more accessible fluorometric output [16]. This assay has been tested against a small panel of PptT inhibitors, but it is unclear if it would be able to detect inhibitors such as 8918 . While 8918 is the best PptT inhibitor reported to date [15], it binds immediately alongside CoA in the active site and might be precluded from binding by a conjugated rhodamine at that position. As our screen uses unadulterated CoA, this would not be a concern.

PPTases have been discussed in the literature as promising drug targets for almost two decades [37]. Despite this, limited progress has been made on progressing inhibitors through drug development pipelines. Thus far the two most promising PPTase inhibitor drug candidates are ML-267, which was identified after high-throughput screening of approximately 330,000 compounds against B. subtilis Sfp [38], but has not yet had efficacy reported against other PPTases; and 8918, which was identified from a whole-cell screen of M. tuberculosis HR7Rv against approximately 90,000 small molecules, with PptT subsequently identified as the drug target [15]. While whole cell screens offer the major advantage that biological activity is guaranteed, at least under the assay conditions employed, target identification is often far more difficult, and high-proportions of timewasting promiscuous "nuisance compounds" are frequently recovered [39]. Moreover, for mycobacterial screens it has been reported that variations in media can substantially alter the spectrum of inhibitors identified from a given chemical collection, raising concerns as to how well host-relevant physicochemical conditions are represented [40]. Conversely, target-based screens for $M$. tuberculosis offer substantial promise in enabling selection of a suitable target upfront [41] and facilitating rational exploration of structure-activity relationships [42]. Our assay therefore meets a need for a simple high-throughput assay that can be applied to directly screen for inhibitors of PptT or other Type II PPTases, or to guide the development of next-generation drug leads based on promising scaffolds such as ML-267 and 8918. Recently, we have also shown that the PCP-domain of BpsA can be rapidly evolved using error-prone mutagenesis to be recognised by other Type II PPTases that initially cannot activate BpsA [35]. This provides a platform to enable the rapid integration of multiple PPTases for inhibitory activity, or to counter-screen the endogenous human PPTase to eliminate drug candidates likely to have undesirable off-target effects. Collectively, we hope this toolbox will prove useful in guiding future medicinal chemistry efforts to design or identify broad spectrum PPTase inhibitors.

Supplementary Materials: The following are available online at https: / www.mdpi.com/article / 10.3390/pharmaceutics13071066/s1, Figure S1: LOPAC1280 screening plate layout, Figure S2: Raw values absorbance values of the LOPAC1280 collection, Figure S3: EC50 values for top compounds, Figure S4: Inhibition of holo-BpsA at an inhibitor concentration of $40 \mu \mathrm{M}$, Figure S5: Kinetic determination of $\mathrm{EC}_{50}$ values.

Author Contributions: Conceptualization, A.S.B., E.N.B. and D.F.A.; Data curation, A.S.B.; Formal analysis, A.S.B.; Funding acquisition, D.F.A.; Investigation, A.S.B.; Methodology, A.S.B., J.G.O. and D.F.A.; Project administration, D.F.A.; Resources, J.G.O. and J.J.; Supervision, E.N.B. and D.F.A.; Validation, A.S.B. and J.G.O.; Writing-original draft, A.S.B. and D.F.A.; Writing-review and editing, A.S.B., J.J., E.N.B. and D.F.A. All authors have read and agreed to the published version of the manuscript. 
Funding: This research was funded by the Royal Society of New Zealand Marsden Fund (Contract VUW0901 to D.F.A.). A.S.B. was supported by a VUW postgraduate scholarship.

Institutional Review Board Statement: Not applicable.

Informed Consent Statement: Not applicable.

Data Availability Statement: The data presented in this study are available on request from the corresponding author.

Conflicts of Interest: The authors declare no conflict of interest. The funders had no role in the design of the study; in the collection, analyses or interpretation of data; in the writing of the manuscript; or in the decision to publish the results.

\section{References}

1. Global Tuberculosis Report. 2020. Available online: https://www.who.int/publications-detail-redirect/9789240013131 (accessed on 5 May 2021).

2. Shetye, G.S.; Franzblau, S.G.; Cho, S. New tuberculosis drug targets, their inhibitors, and potential therapeutic impact. Transl. Res. 2020, 220, 68-97. [CrossRef] [PubMed]

3. Neyrolles, O.; Guilhot, C. Recent advances in deciphering the contribution of Mycobacterium tuberculosis lipids to pathogenesis. Tuberculosis 2011, 91, 187-195. [CrossRef] [PubMed]

4. Daffé, M. The cell envelope of tubercle bacilli. Tuberculosis 2015, 95, S155-S158. [CrossRef] [PubMed]

5. Karakousis, P.C.; Bishai, W.R.; Dorman, S.E. Mycobacterium tuberculosiscell envelope lipids and the host immune response. Cell. Microbiol. 2004, 6, 105-116. [CrossRef]

6. Gokhale, R.S.; Saxena, P.; Chopra, T.; Mohanty, D. Versatile polyketide enzymatic machinery for the biosynthesis of complex mycobacterial lipids. Nat. Prod. Rep. 2007, 24, 267-277. [CrossRef]

7. McMahon, M.D.; Rush, J.S.; Thomas, M.G. Analyses of MbtB, MbtE, and MbtF Suggest Revisions to the Mycobactin Biosynthesis Pathway in Mycobacterium tuberculosis. J. Bacteriol. 2012, 194, 2809-2818. [CrossRef]

8. Beld, J.; Sonnenschein, E.; Vickery, C.R.; Noel, J.P.; Burkart, M.D. The phosphopantetheinyl transferases: Catalysis of a posttranslational modification crucial for life. Nat. Prod. Rep. 2014, 31, 61-108. [CrossRef]

9. Foley, T.L.; Young, B.S.; Burkart, M.D. Phosphopantetheinyl transferase inhibition and secondary metabolism. FEBS J. 2009, 276, 7134-7145. [CrossRef]

10. Chalut, C.; Botella, L.; de Sousa-D'Auria, C.; Houssin, C.; Guilhot, C. The nonredundant roles of two $4^{\prime}$-phosphopantetheinyl transferases in vital processes of Mycobacteria. Proc. Natl. Acad. Sci. USA 2006, 103, 8511-8516. [CrossRef] [PubMed]

11. Zimhony, O.; Schwarz, A.; Raitses-Gurevich, M.; Peleg, Y.; Dym, O.; Albeck, S.; Burstein, Y.; Shakked, Z. AcpM, the Meromycolate Extension Acyl Carrier Protein of Mycobacterium tuberculosis, Is Activated by the 4 '-Phosphopantetheinyl Transferase PptT, a Potential Target of the Multistep Mycolic Acid Biosynthesis. Biochemistry 2015, 54, 2360-2371. [CrossRef] [PubMed]

12. Sassetti, C.M.; Boyd, D.H.; Rubin, E.J. Comprehensive identification of conditionally essential genes in mycobacteria. Proc. Natl. Acad. Sci. USA 2001, 98, 12712-12717. [CrossRef]

13. Leblanc, C.; Prudhomme, T.; Tabouret, G.; Ray, A.; Burbaud, S.; Cabantous, S.; Mourey, L.; Guilhot, C.; Chalut, C. 4'Phosphopantetheinyl Transferase PptT, a New Drug Target Required for Mycobacterium tuberculosis Growth and Persistence In Vivo. PLOS Pathog. 2012, 8, e1003097. [CrossRef] [PubMed]

14. Quadri, L.E.; Sello, J.; Keating, T.A.; Weinreb, P.; Walsh, C.T. Identification of a Mycobacterium tuberculosis gene cluster encoding the biosynthetic enzymes for assembly of the virulence-conferring siderophore mycobactin. Chem. Biol. 1998, 5, 631-645. [CrossRef]

15. Ballinger, E.; Mosior, J.; Hartman, T.; Burns-Huang, K.; Gold, B.; Morris, R.; Goullieux, L.; Blanc, I.; Vaubourgeix, J.; Lagrange, S.; et al. Opposing reactions in coenzyme A metabolism sensitize Mycobacterium tuberculosis to enzyme inhibition. Science 2019, 363, eaau8959. [CrossRef] [PubMed]

16. Vickery, C.R.; Kosa, N.M.; Casavant, E.P.; Duan, S.; Noel, J.P.; Burkart, M.D. Structure, Biochemistry, and Inhibition of Essential 4'-Phosphopantetheinyl Transferases from Two Species of Mycobacteria. ACS Chem. Biol. 2014, 9, 1939-1944. [CrossRef]

17. Jung, J.; Bashiri, G.; Johnston, J.M.; Brown, A.S.; Ackerley, D.F.; Baker, E.N. Crystal structure of the essential Mycobacterium tuberculosis phosphopantetheinyl transferase PptT, solved as a fusion protein with maltose binding protein. J. Struct. Biol. 2014, 188, 274-278. [CrossRef] [PubMed]

18. Reuter, K.; Mofid, M.R.; Marahiel, M.A.; Ficner, R. Crystal structure of the surfactin synthetase-activating enzyme Sfp: A prototype of the $4^{\prime}$-phosphopantetheinyl transferase superfamily. EMBO J. 1999, 18, 6823-6831. [CrossRef]

19. Yasgar, A.; Foley, T.L.; Jadhav, A.; Inglese, J.; Burkart, M.D.; Simeonov, A. A strategy to discover inhibitors of Bacillus subtilis surfactin-type phosphopantetheinyl transferase. Mol. BioSyst. 2009, 6, 365-375. [CrossRef]

20. Duckworth, B.P.; Aldrich, C.C. Development of a high-throughput fluorescence polarization assay for the discovery of phosphopantetheinyl transferase inhibitors. Anal. Biochem. 2010, 403, 13-19. [CrossRef]

21. Kosa, N.M.; Foley, T.L.; Burkart, M.D. Fluorescent techniques for discovery and characterization of phosphopantetheinyl transferase inhibitors. J. Antibiot. 2013, 67, 113-120. [CrossRef] 
22. Owen, J.G.; Copp, J.N.; Ackerley, D.F. Rapid and flexible biochemical assays for evaluating $4^{\prime}$-phosphopantetheinyl transferase activity. Biochem. J. 2011, 436, 709-717. [CrossRef]

23. Takahashi, H.; Kumagai, T.; Kitani, K.; Mori, M.; Matoba, Y.; Sugiyama, M. Cloning and Characterization of a Streptomyces Single Module Type Non-ribosomal Peptide Synthetase Catalyzing a Blue Pigment Synthesis. J. Biol. Chem. 2007, 282, 9073-9081. [CrossRef]

24. Pettersen, E.F.; Goddard, T.D.; Huang, C.C.; Couch, G.S.; Greenblatt, D.M.; Meng, E.C.; Ferrin, T.E. UCSF Chimera-A visualization system for exploratory research and analysis. J. Comput. Chem. 2004, 25, 1605-1612. [CrossRef]

25. Brown, A.S.; Robins, K.; Ackerley, D.F. A sensitive single-enzyme assay system using the non-ribosomal peptide synthetase BpsA for measurement of L-glutamine in biological samples. Sci. Rep. 2017, 7, srep41745. [CrossRef]

26. Owen, J.G.; Robins, K.; Parachin, N.; Ackerley, D.F. A functional screen for recovery of $4{ }^{\prime}$-phosphopantetheinyl transferase and associated natural product biosynthesis genes from metagenome libraries. Environ. Microbiol. 2012, 14, 1198-1209. [CrossRef] [PubMed]

27. Zhang, J.-H.; Chung, T.D.Y.; Oldenburg, K.R. A Simple Statistical Parameter for Use in Evaluation and Validation of High Throughput Screening Assays. J. Biomol. Screen. 1999, 4, 67-73. [CrossRef] [PubMed]

28. The Pandas Development Team. Pandas-Dev/Pandas: Pandas 1.2.4. Zenodo 2021. [CrossRef]

29. Waskom, M.L. seaborn: Statistical data visualization. J. Open Source Softw. 2021, 6, 3021. [CrossRef]

30. Rottier, K.; Faille, A.; Prudhomme, T.; Leblanc, C.; Chalut, C.; Cabantous, S.; Guilhot, C.; Mourey, L.; Pedelacq, J.-D. Detection of soluble co-factor dependent protein expression in vivo: Application to the $4^{\prime}$-phosphopantetheinyl transferase PptT from Mycobacterium tuberculosis. J. Struct. Biol. 2013, 183, 320-328. [CrossRef] [PubMed]

31. Brown, A.S.; Calcott, M.J.; Collins, V.M.; Owen, J.G.; Ackerley, D.F. The indigoidine synthetase BpsA provides a colorimetric ATP assay that can be adapted to quantify the substrate preferences of other NRPS enzymes. Biotechnol. Lett. 2020, 42, $2665-2671$. [CrossRef]

32. Feng, B.Y.; Shoichet, B.K. A detergent-based assay for the detection of promiscuous inhibitors. Nat. Protoc. 2006, 1, 550-553. [CrossRef]

33. Baell, J.B.; Nissink, J.W.M. Seven Year Itch: Pan-Assay Interference Compounds (PAINS) in 2017-Utility and Limitations. ACS Chem. Biol. 2018, 13, 36-44. [CrossRef] [PubMed]

34. Brown, A.S.; Ackerley, D.F.; Calcott, M.J. High-Throughput Screening for Inhibitors of the SARS-CoV-2 Protease Using a FRET-Biosensor. Molecules 2020, 25, 4666. [CrossRef] [PubMed]

35. Brown, A.S.; Sissons, J.A.; Owen, J.G.; Ackerley, D.F. Directed Evolution of the Nonribosomal Peptide Synthetase BpsA to Enable Recognition by the Human Phosphopantetheinyl Transferases for Counter-Screening Antibiotic Candidates. ACS Infect. Dis. 2020, 6, 2879-2886. [CrossRef] [PubMed]

36. Johns, A.; Scharf, D.; Gsaller, F.; Schmidt, H.; Heinekamp, T.; Straßburger, M.; Oliver, J.D.; Birch, M.; Beckmann, N.; Dobb, K.S.; et al. A Nonredundant Phosphopantetheinyl Transferase, PptA, Is a Novel Antifungal Target That Directs Secondary Metabolite, Siderophore, and Lysine Biosynthesis in Aspergillus fumigatus and Is Critical for Pathogenicity. mBio 2017, 8, e01504-16. [CrossRef] [PubMed]

37. Gilbert, A.M.; Kirisits, M.; Toy, P.; Nunn, D.S.; Failli, A.; Dushin, E.G.; Novikova, E.; Petersen, P.J.; Joseph-McCarthy, D.; McFadyen, I.; et al. Anthranilate 4H-oxazol-5-ones: Novel small molecule antibacterial acyl carrier protein synthase (AcpS) inhibitors. Bioorg. Med. Chem. Lett. 2004, 14, 37-41. [CrossRef]

38. Foley, T.L.; Rai, G.; Yasgar, A.; Daniel, T.; Baker, H.L.; Attene-Ramos, M.; Kosa, N.M.; Leister, W.; Burkart, M.D.; Jadhav, A.; et al. 4-(3-Chloro-5-(trifluoromethyl)pyridin-2-yl)-N-(4-methoxypyridin-2-yl)piperazine-1-carbothioamide (ML267), a Potent Inhibitor of Bacterial Phosphopantetheinyl Transferase That Attenuates Secondary Metabolism and Thwarts Bacterial Growth. J. Med. Chem. 2014, 57, 1063-1078. [CrossRef]

39. Matano, L.M.; Morris, H.G.; Wood, B.M.; Meredith, T.C.; Walker, S. Accelerating the discovery of antibacterial compounds using pathway-directed whole cell screening. Bioorg. Med. Chem. 2016, 24, 6307-6314. [CrossRef] [PubMed]

40. Miller, C.H.; Nisa, S.; Dempsey, S.; Jack, C.; O’Toole, R. Modifying Culture Conditions in Chemical Library Screening Identifies Alternative Inhibitors of Mycobacteria. Antimicrob. Agents Chemother. 2009, 53, 5279-5283. [CrossRef]

41. Abrahams, K.A.; Besra, G.S. Mycobacterial drug discovery. RSC Med. Chem. 2020, 11, 1354-1365. [CrossRef]

42. Kana, B.D.; Karakousis, P.C.; Parish, T.; Dick, T. Future target-based drug discovery for tuberculosis? Tuberculosis 2014, 94, 551-556. [CrossRef] [PubMed] 